\title{
Mosquitoes and Zika: time to harness genetic modification?
}

\author{
With vaccines years from being developed, will the threat of Zika virus push bodies such as WHO \\ to embrace a new solution? Michael Brooks reports
}

\author{
Michael Brooks science journalist, London, UK
}

\begin{abstract}
Mosquitoes kill hundreds of thousands of people each year through transmission of diseases such as malaria, dengue fever, and yellow fever. However, in the last year, death has been displaced as the greatest fear in the public consciousness.

The spread of the Zika virus, which causes devastating defects in developing fetuses, has created a new urgency in dealing with mosquito-borne disease.

For the first time, the World Health Organization has recommended "carefully planned pilot deployment" for a genetically modified mosquito that has proved effective in small scale field trials. ${ }^{1}$
\end{abstract}

The mosquito in question has been developed by researchers at Oxitec, a company based in Oxford. Oxitec inserts a gene into the male Aedes aegypti mosquito, thought to be the primary vector in the current Zika outbreak. The gene prevents expression of certain other genes and results in over $95 \%$ of the altered males' offspring dying before they reach maturity.

When Oxitec releases these modified mosquitoes into the wild, they mate with wild females. The offspring die before being able to reproduce and the local population collapses. "We have seen $90 \%$ suppression of A aegypti in every field trial we've run," says Simon Warner, chief scientific officer of Oxitec. "If you're going to use insecticide, the best you get is $50 \%$ suppression."

In Brazil, the company has now moved beyond field trials. Having received approval from the National Technical Biosafety Commission, Oxitec's technology is now being deployed in Piracicaba, a city in the south east of the country, where the company is building a factory that will produce enough modified mosquitoes to protect 300000 people from mosquito-borne diseases. The Pan American Health Organization, WHO's regional office for the Americas, has also offered technical support for other countries that wish to use the modified mosquitoes. $^{3}$

\section{Promising technology}

Other researchers, using newer gene modification techniques yet to make it out of the laboratory, are also raising new hopes of defeating the mosquito menace. They are using clustered, regularly interspaced, short palindromic repeat (CRISPR) with the enzyme Cas9, which evolved in bacteria as a tool for fighting off viruses. Cas9 is an RNA guided nuclease that excises the DNA that a virus inserts into a bacterium. Researchers can design their own RNA to tell the enzyme where to cut the genome. They put their customised RNA, Cas9, and a section of replacement DNA into a virus, which is then allowed to infect the cell nucleus to be edited. Once the Cas9 and RNA have done their work, the cell's repair mechanism inserts the new strand of DNA.

Though it is very early days for CRISPR, with techniques still being explored and refined, there are several ways that it could eventually be put to work to suppress mosquito populations.

One, published this year by Austin Burt, professor of evolutionary genetics at Imperial College London, and colleagues, involves turning off genes that direct the production of eggs in females of the species Anopheles gambiae, which transmits malaria in sub-Saharan Africa. ${ }^{4}$ Another technique, just beginning to be successfully implemented in the laboratory, is to make mosquitoes resistant to infection by the Plasmodium parasite that causes malaria. ${ }^{5}$

A third prospect, raised by Zach Adelman of Virginia Tech is to isolate the "M factor," the set of genes that has an important role in determining the sex of a mosquito's offspring. ${ }^{6}$ Though challenging, it opens up the possibility of using CRISPR to skew the sex ratio of a mosquito population towards male dominance. Since the females bite (and thus transmit parasites) and lay eggs, this could drastically reduce the transmission of disease. "It is being tested, but there is still a way to go," Adelman says. "Time will tell how hard it will be to utilise the $M$ Factor in a genetically engineered mosquito strain effectively." 
The effectiveness of these modifications can be radically improved through an innovation known as a "gene drive." Engineer a change in DNA and it will appear in only one of the pair of chromosomes involved in reproduction. That means it normally has only a 50-50 chance of being taken up in the next generation. Last year, however, Ethan Bier and Valentino Gantz of the University of California, San Diego, worked out how to use CRISPR-Cas9 to copy that change into the second chromosome in fruit flies. ${ }^{7}$ This means that almost all offspring will inherit the change.

A team led by Anthony James at the University of California, Irvine, has now engineered a gene drive for mosquitoes. ${ }^{8}$ Their studies rendered $99 \%$ of offspring in a mosquito population resistant to infection with the Plasmodium parasite. Although James's primary focus is dengue and malaria, the same techniques could be used to help stem the Zika outbreak. "What we have developed is a blueprint for how to do it that could be applied to a number of mosquito vectors and pathogens," James says.

\section{Public acceptability}

Despite the substantial progress towards controlling a range of mosquito-borne diseases, we are unlikely to see CRISPR based solutions outside the lab in the near future, James warns. "The timetable is contingent on regulatory and community engagement activities," he says. "I have no basis for estimating how long this would take or if it would be successful."

CRISPR's strength may also be its downfall. Once released, the modified mosquitoes will become dominant. That means having genetically modified organisms as a permanent fixture in the environment-or wiping out the species altogether. Such large interventions have traditionally made the public nervous, but there are indications of a changing mood. Purdue University researchers have found the US public overwhelmingly in favour of controlling the spread of the Zika through the use of genetically engineered mosquitoes. " 9 "The fact that Zika is receiving such intensive press, and the fact that there are hardly any weapons to fight the disease besides vector control, does help tilt public opinion," says Marcelo Jacobs-Lorena, a professor at Johns Hopkins School of Public Health.

Despite the best efforts of public health programmes, it has so far proved almost impossible to control mosquito populations. Female mosquitoes will seize on any body of water, such as a rain flooded disused oil drum as a site to lay eggs. Encouraging the use of nets over beds has had some effect, as has the use of insecticide spray. None of this has halted the advance of Zika, however.

That said, it has yet to be proved that genetic modification with CRISPR can do better. While the Zika outbreak in the Americas has helped speed parts of the research process along, increased interest, and stimulated new funding initiatives, it hasn't accelerated approval for trials, which have to be carried out with due process. Field trials for CRISPR are probably at least five years away, Burt says. Although the Oxitec mosquito is further along, some have raised doubts about whether Oxitec's approach can be deployed fast enough, and at a sufficiently large scale, to make a substantial impact on Zika. ${ }^{10}$

There is also uncertainty about whether the precise details of the threat posed by Zika will create a moving target. WHO has said the number of cases of Zika in Latin America is falling, probably because of seasonal factors. However, as Europe warms, the virus may spread to new locations. Researchers also face the prospect of a new vector: there are unconfirmed suggestions that mosquito species other than A aegypti may be able to carry the Zika virus. ${ }^{11}{ }^{12}$ If that is the case, not only will the disease spread more easily, genetic modification techniques may have to broaden to other species, creating another regulatory hurdle.

Competing interests: I have read and understood BMJ policy on declaration of interests and have no relevant interests to declare. Provenance and peer review: Commissioned; not externally peer reviewed.

WHO. Mosquito (vector) control emergency response and preparedness for Zika virus. 2016. http://www.who.int/neglected_diseases/news/mosquito_vector_control_response/ en/

2 Carvalho DO, McKemey AR, Garziera L, et al. Suppression of a field population of Aedes aegypti in Brazil by sustained release of transgenic male mosquitoes. PLoS Negl Trop Dis 2015:9:e0003864. doi:10.1371/journal.pntd.0003864 pmid:26135160.

3 Pan American Health Organization. PAHO offers to provide technical support for pilot studies of new mosquito control technologies. Press release, 8 Apr 2016. http://www. paho.org $/ \mathrm{hq} /$ index.php?option=com_content\&view=article\&id $=11899 \&$ Itemid $=1926 \&$ lang=en.

4 Hammond A, Galizi R, Kyrou K, et al. A CRISPR-Cas9 gene drive system targeting female reproduction in the malaria mosquito vector Anopheles gambiae. Nat Biotechnol 2016:34:78-83, doi:10.1038/nbt.3439. pmid:26641531.

5 Isaacs AT, Li F, Jasinskiene N, et al. Engineered resistance to Plasmodium falciparum development in transgenic Anopheles stephensi. PLoS Pathog 2011;7:e1002017. doi:10. 1371/journal.ppat.1002017 pmid:21533066.

6 Adelman ZN, Tu Z. Control of mosquito-borne infectious diseases: sex and gene drive. Trends Parasitol 2016;32:219-29. doi:10.1016/.pt.2015.12.003 pmid:26897660.

7 Gantz VM, Bier E. Genome editing. The mutagenic chain reaction: a method for converting heterozygous to homozygous mutations. Science 2015;348:442-4. doi:10.1126/science. aaa5945 pmid:25908821.

8 Gantz VM, Jasinskiene N, Tatarenkova O, et al. Highly efficient Cas9-mediated gene drive for population modification of the malaria vector mosquito Anopheles stephensi. Proc Natl Acad Sci U S A 2015;112:E6736-43. doi:10.1073/pnas.1521077112 pmid: 26598698.

9 Purdue Extension. US public overwhelmingly supports use of GMO mosquitoes to help control Zika virus. 2016. https://extension.purdue.edu/Pages/article.aspx?intltemID=14074

10 Suresh A. Are genetically engineered mosquitoes realistic solution to Zika? 15 Feb 2016. https://www.geneticliteracyproject.org/2016/02/05/genetically-engineered-mosquitoesrealistic-solution-zika/].

11 Worth K. A common US mosquito may transmit Zika virus, study says. PBS Newshour, $7 \mathrm{Mar}$ 2016. http://www.pbs.org/newshour/rundown/a-common-u-s-mosquito-may-transmitzika-virus-study-says/

12 Lafrance A. The sneak-attack mosquito. Atlantic 2016 Apr 25. http://www.theatlantic.com/ science/archive/2016/04/aedes-aegypt/479619/

Published by the BMJ Publishing Group Limited. For permission to use (where not already granted under a licence) please go to http://group.bmj.com/group/rights-licensing/ permissions 